\title{
3D printing of composites: design parameters and flexural performance
}

\begin{tabular}{|r|l|}
\hline Journal: & Rapid Prototyping Journal \\
\hline Manuscript ID & RPJ-07-2019-0188.R1 \\
\hline Manuscript Type: & Original Article \\
\hline Keywords: & $\begin{array}{l}\text { Additive manufacturing, Composites, Markforged, Carbon fibre/Nylon, } \\
\text { Fibre location, Flexural properties }\end{array}$ \\
\hline \multicolumn{2}{|l}{} \\
\hline
\end{tabular}

\section{SCHOLARONE \\ Manuscripts}


Table 1 - Fibre volume fraction of 3D printed specimens

\begin{tabular}{|c|c|c|}
\hline $\begin{array}{c}\text { Sample } \\
\text { Number }\end{array}$ & $\begin{array}{c}\text { Fibre } \\
\text { Volume } \\
\text { fraction } \\
\left(\boldsymbol{V}_{\boldsymbol{f}} \%\right)\end{array}$ & $\begin{array}{c}\text { Internal layer } \\
\text { Composition }\end{array}$ \\
\hline 0 & $\mathbf{0}$ & $56 \mathrm{~N}$ \\
\hline 1 & $\mathbf{4 . 2 1}$ & $4 \mathrm{~N}|1 \mathrm{C}| 46 \mathrm{~N}|1 \mathrm{C}| 4 \mathrm{~N}$ \\
\hline 2 & $\mathbf{8 . 1 8}$ & $4 \mathrm{~N}|2 \mathrm{C}| 44 \mathrm{~N}|2 \mathrm{C}| 4 \mathrm{~N}$ \\
\hline 3 & $\mathbf{1 2 . 0 4}$ & $4 \mathrm{~N}|3 \mathrm{C}| 42 \mathrm{~N}|3 \mathrm{C}| 4 \mathrm{~N}$ \\
\hline 4 & $\mathbf{1 5 . 5 9}$ & $4 \mathrm{~N}|4 \mathrm{C}| 40 \mathrm{~N}|4 \mathrm{C}| 4 \mathrm{~N}$ \\
\hline 5 & $\mathbf{1 8 . 9 6}$ & $4 \mathrm{~N}|5 \mathrm{C}| 38 \mathrm{~N}|5 \mathrm{C}| 4 \mathrm{~N}$ \\
\hline 6 & $\mathbf{2 2 . 1 5}$ & $4 \mathrm{~N}|6 \mathrm{C}| 36 \mathrm{~N}|6 \mathrm{C}| 4 \mathrm{~N}$ \\
\hline 7 & $\mathbf{2 5 . 2 1}$ & $4 \mathrm{~N}|7 \mathrm{C}| 34 \mathrm{~N}|7 \mathrm{C}| 4 \mathrm{~N}$ \\
\hline 8 & $\mathbf{2 8 . 1 0}$ & $4 \mathrm{~N}|8 \mathrm{C}| 32 \mathrm{~N}|8 \mathrm{C}| 4 \mathrm{~N}$ \\
\hline 9 & $\mathbf{3 0 . 9 1}$ & $4 \mathrm{~N}|9 \mathrm{C}| 30 \mathrm{~N}|9 \mathrm{C}| 4 \mathrm{~N}$ \\
\hline 10 & $\mathbf{3 3 . 5 6}$ & $4 \mathrm{~N}|10 \mathrm{C}| 28 \mathrm{~N}|10 \mathrm{C}| 4 \mathrm{~N}$ \\
\hline 11 & $\mathbf{3 6 . 0 7}$ & $4 \mathrm{~N}|11 \mathrm{C}| 26 \mathrm{~N}|11 \mathrm{C}| 4 \mathrm{~N}$ \\
\hline 12 & $\mathbf{3 8 . 4 6}$ & $4 \mathrm{~N}|12 \mathrm{C}| 24 \mathrm{~N}|12 \mathrm{C}| 4 \mathrm{~N}$ \\
\hline 13 & $\mathbf{4 0 . 7 5}$ & $4 \mathrm{~N}|13 \mathrm{C}| 22 \mathrm{~N}|13 \mathrm{C}| 4 \mathrm{~N}$ \\
\hline 14 & $\mathbf{4 2 . 9 8}$ & $4 \mathrm{~N}|14 \mathrm{C}| 20 \mathrm{~N}|14 \mathrm{C}| 4 \mathrm{~N}$ \\
\hline 15 & $\mathbf{4 5 . 1 3}$ & $4 \mathrm{~N}|15 \mathrm{C}| 18 \mathrm{~N}|15 \mathrm{C}| 4 \mathrm{~N}$ \\
\hline 16 & $\mathbf{4 7 . 1 4}$ & $4 \mathrm{~N}|16 \mathrm{C}| 16 \mathrm{~N}|16 \mathrm{C}| 4 \mathrm{~N}$ \\
\hline 17 & $\mathbf{5 4 . 4 9}$ & $4 \mathrm{~N}|20 \mathrm{C}| 8 \mathrm{~N}|20 \mathrm{C}| 4 \mathrm{~N}$ \\
\hline 18 & $\mathbf{5 9 . 2 8}$ & $4 \mathrm{~N}|22 \mathrm{C}| 4 \mathrm{~N}|22 \mathrm{C}| 4 \mathrm{~N}$ \\
\hline 19 & $\mathbf{6 4 . 7 8}$ & $4 \mathrm{~N}|48 \mathrm{C}| 4 \mathrm{~N}$ \\
\hline
\end{tabular}

$(\mathrm{N}=$ Nylon, $\mathrm{C}=$ Carbon fibre $)$

Table 2 - Various locations of fibre layers

\begin{tabular}{|c|c|}
\hline $\begin{array}{c}\text { Sample } \\
\text { Number }\end{array}$ & $\begin{array}{c}\text { Internal layer } \\
\text { Composition }\end{array}$ \\
\hline 5 & $\mathbf{4 N}|\mathbf{5 C}| \mathbf{3 8 N}|\mathbf{5 C}| \mathbf{4 N}$ \\
\hline 20 & $\mathbf{2 3 N}|\mathbf{1 0 C}| \mathbf{2 3 N}$ \\
\hline 21 & $\begin{array}{c}\mathbf{5 N}|\mathbf{2 C}| \mathbf{9 N}|\mathbf{2 C}| \mathbf{9 N} \mid \\
\mathbf{2 C}|\mathbf{9 N}| \mathbf{2 C}|\mathbf{9 N}| \mathbf{2 C} \mid \mathbf{5 N}\end{array}$ \\
\hline 22 & $\mathbf{1 6 N}|\mathbf{5 C}| \mathbf{1 4 N}|\mathbf{5 C}| \mathbf{1 6 N}$ \\
\hline
\end{tabular}

$(\mathrm{N}=$ Nylon, $\mathrm{C}=$ Carbon fibre $)$

Table 3 - Various fibre orientations

\begin{tabular}{|c|c|c|c|}
\cline { 2 - 4 } \multicolumn{1}{c|}{} & $\begin{array}{c}\text { Sample } \\
\text { Number }\end{array}$ & $\begin{array}{c}\text { Internal layer } \\
\text { Composition }\end{array}$ & $\begin{array}{c}\text { Fibre } \\
\text { Angle }\end{array}$ \\
\cline { 2 - 4 } \multicolumn{1}{c|}{} & 23 & $4 \mathrm{~N}|5 \mathrm{C}| 38 \mathrm{~N}|5 \mathrm{C}| 4 \mathrm{~N}$ & $\mathbf{+ 4 5}^{\circ}+\mathbf{4 5}$ \\
\cline { 2 - 3 } \multicolumn{1}{c|}{} & 24 & $4 \mathrm{~N}|5 \mathrm{C}| 38 \mathrm{~N}|5 \mathrm{C}| 4 \mathrm{~N}$ & $\mathbf{+ 4 5}^{\circ} / \mathbf{4 5}$ \\
\hline 25 & $4 \mathrm{~N}|5 \mathrm{C}| 38 \mathrm{~N}|5 \mathrm{C}| 4 \mathrm{~N}$ & $\mathbf{+ 9 0} \%+\mathbf{9 0}$ & \\
\hline 26 & $4 \mathrm{~N}|5 \mathrm{C}| 38 \mathrm{~N}|5 \mathrm{C}| 4 \mathrm{~N}$ & $\mathbf{+ 9 0} /+\mathbf{0}^{\circ}$ \\
\hline
\end{tabular}




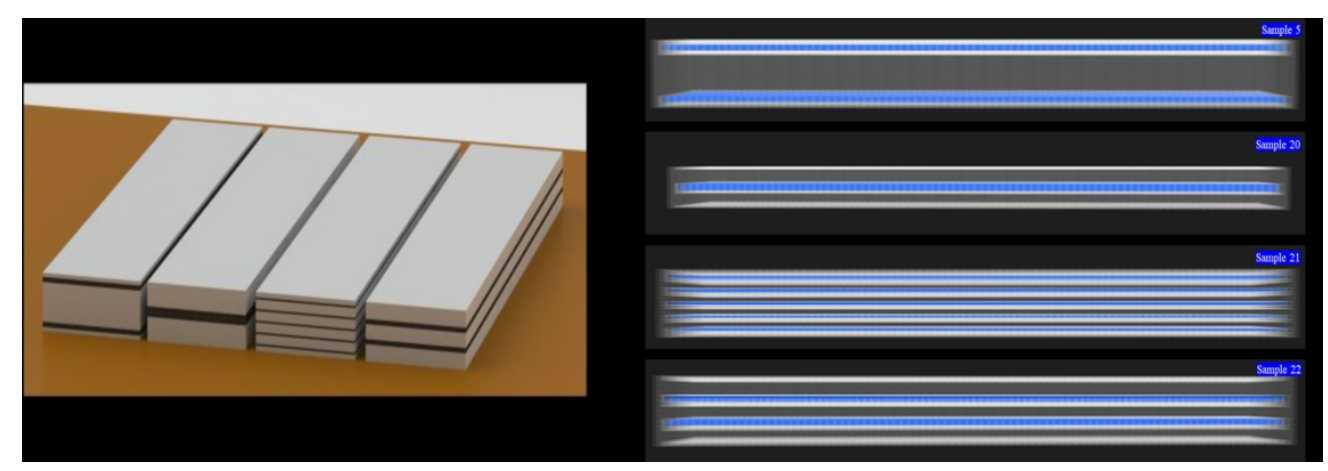

Figure 1-Examples of fibre layer locations (Samples 5, 20, $21 \& 22$ from top to bottom) $302 \times 103 \mathrm{~mm}(149 \times 149 \mathrm{DPI})$ 


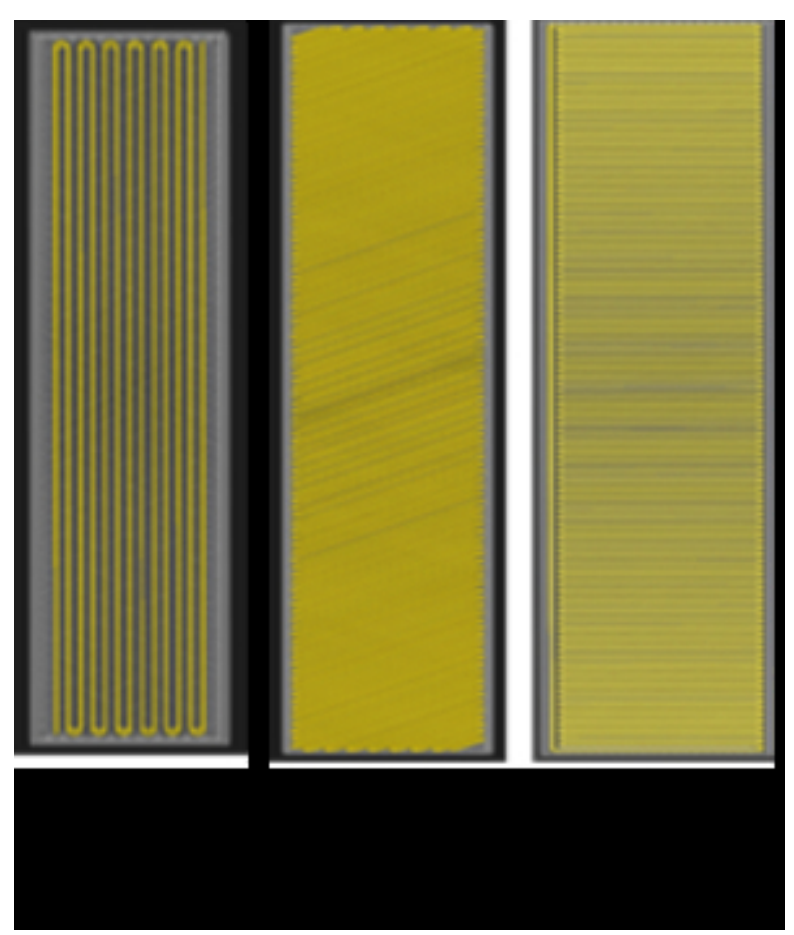

Figure 2-Fibres orientations $50 \times 59 \mathrm{~mm}(149 \times 149 \mathrm{DPI})$ 


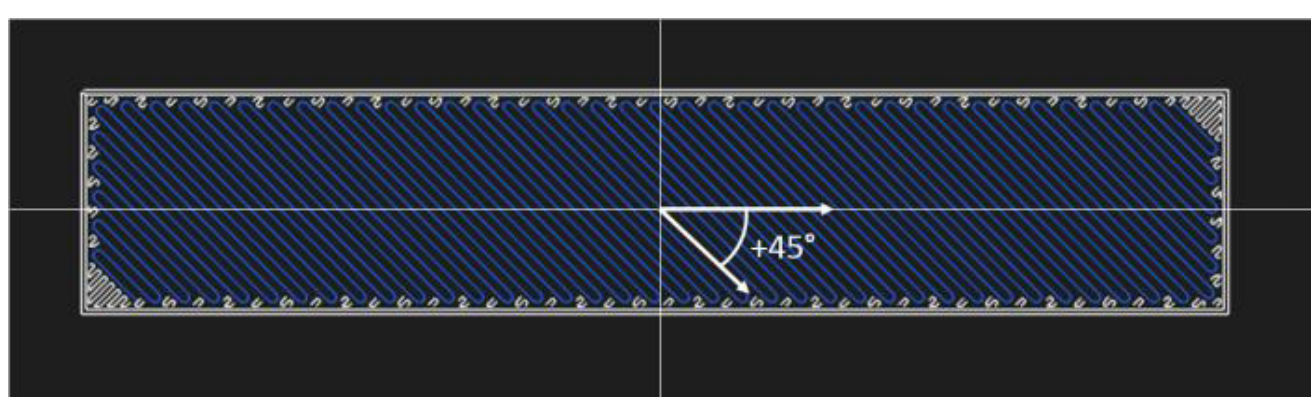

Figure 3 - fibre layer cross-section $185 \times 53 \mathrm{~mm}(96 \times 96 \mathrm{DPI})$ 


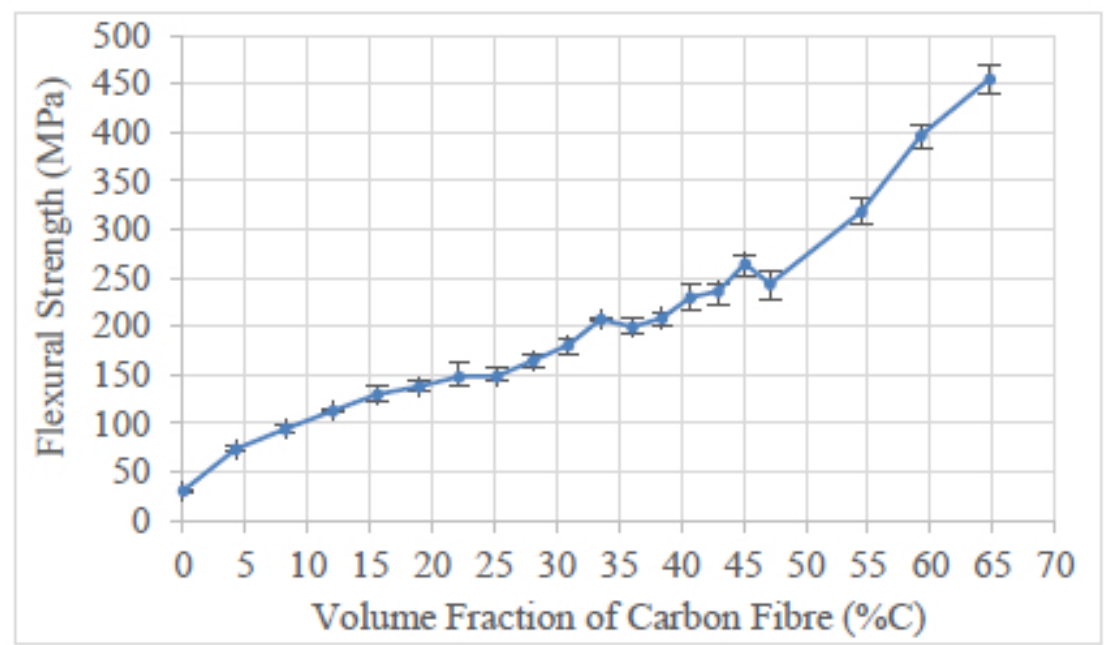

Figure 4 - The relationship between volume fraction and flexural strength $114 \times 66 \mathrm{~mm}(96 \times 96 \mathrm{DPI})$ 


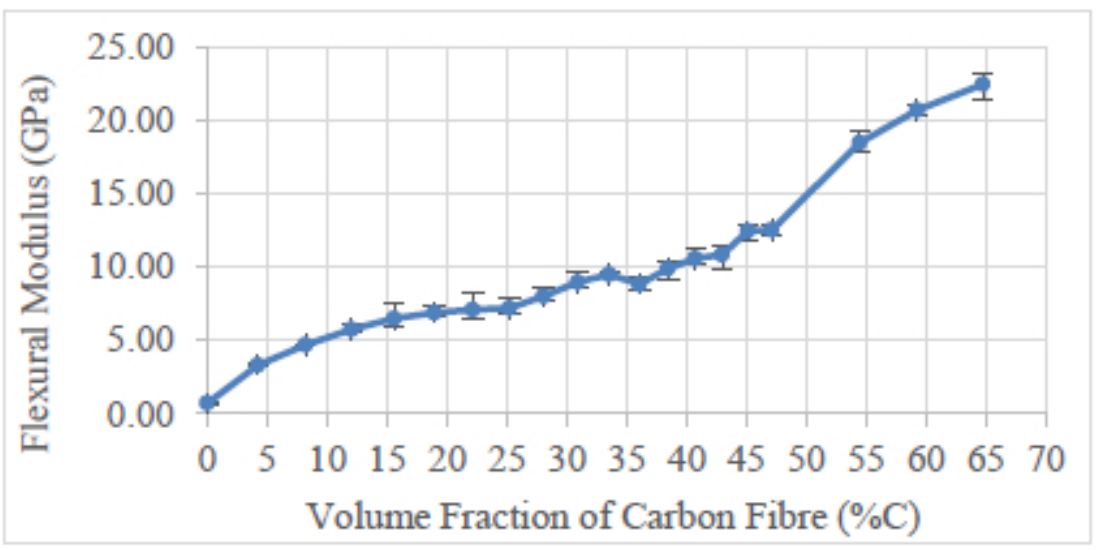

Figure 5 - The relationship between volume fraction and flexural modulus $113 \times 56 \mathrm{~mm}(96 \times 96 \mathrm{DPI})$ 


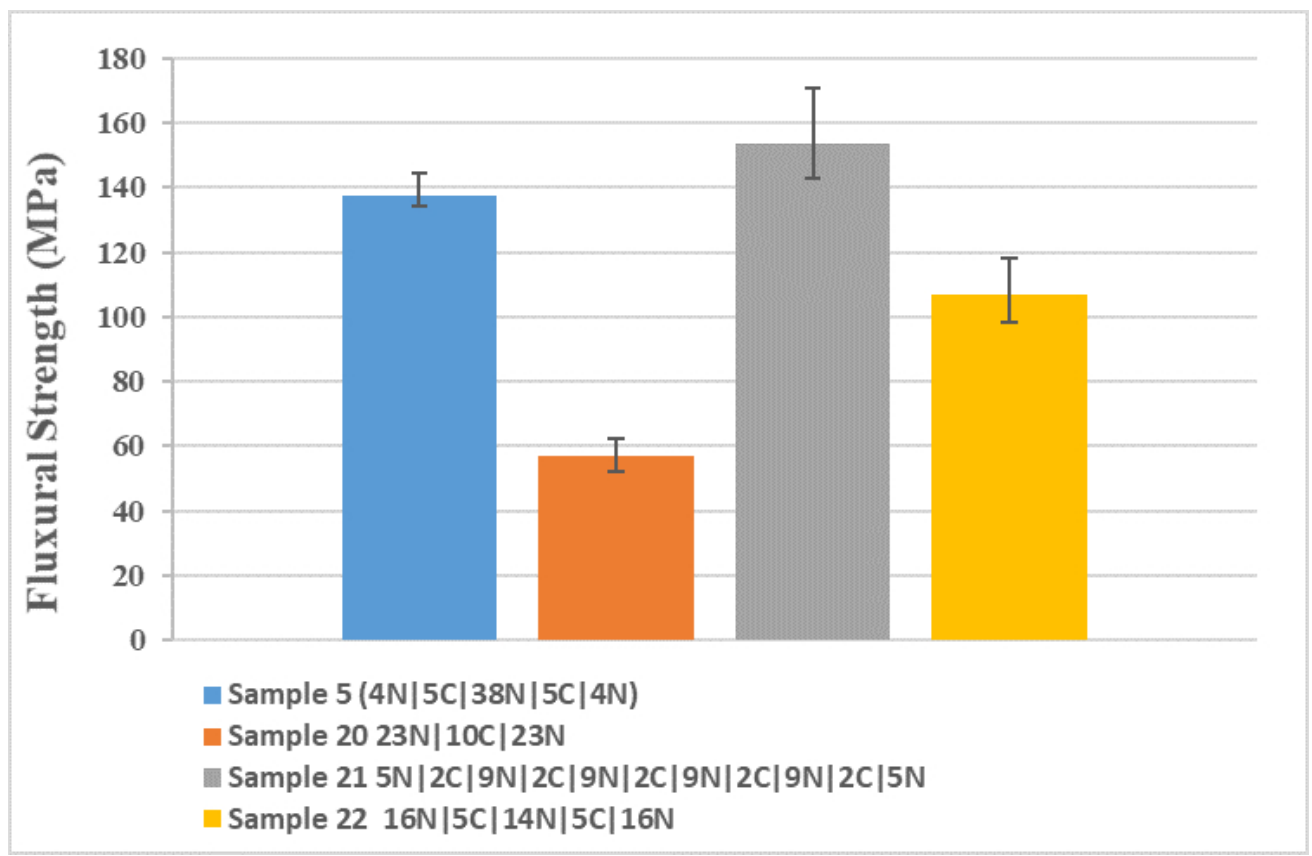

Figure 6 - Averaged flexural strength for different fibre locations

$$
127 \times 82 \mathrm{~mm}(150 \times 150 \mathrm{DPI})
$$


Figure 7 - Averaged flexural properties and their average -to-weight ratios for different fibre locations $129 \times 78 \mathrm{~mm}(150 \times 150 \mathrm{DPI})$ 


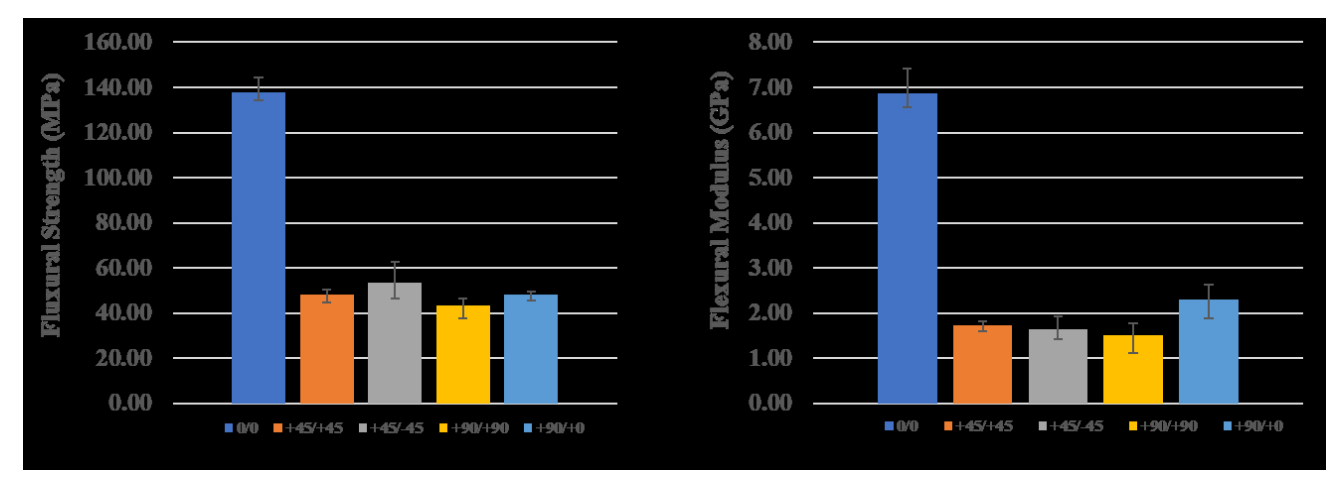

Figure 8 - Relationship Between Fibre Orientation and flexural Properties $221 \times 77 \mathrm{~mm}(150 \times 150 \mathrm{DPI})$ 


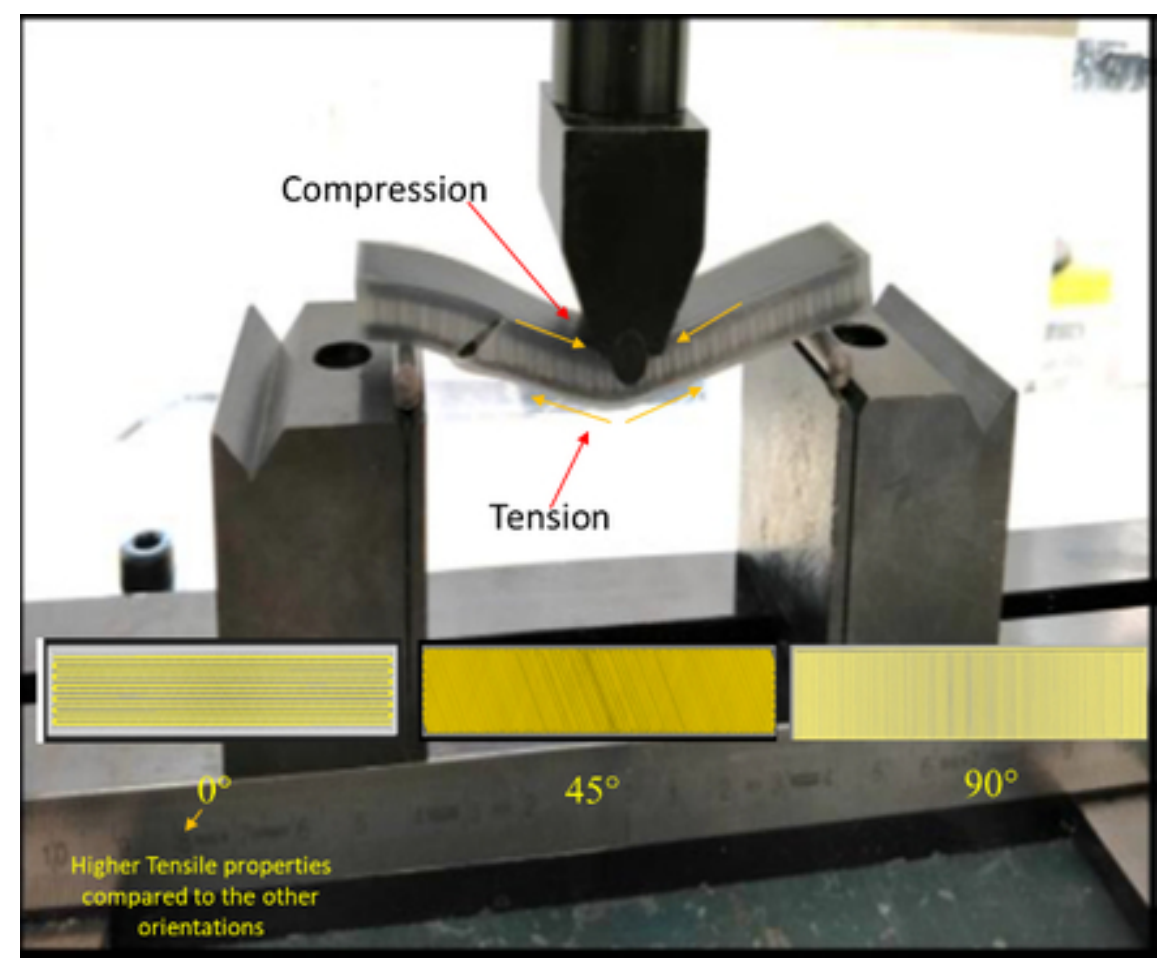

Figure 9 - Relationship Between Fibre Orientation and flexural loads $73 \times 61 \mathrm{~mm}(150 \times 150 \mathrm{DPI})$ 


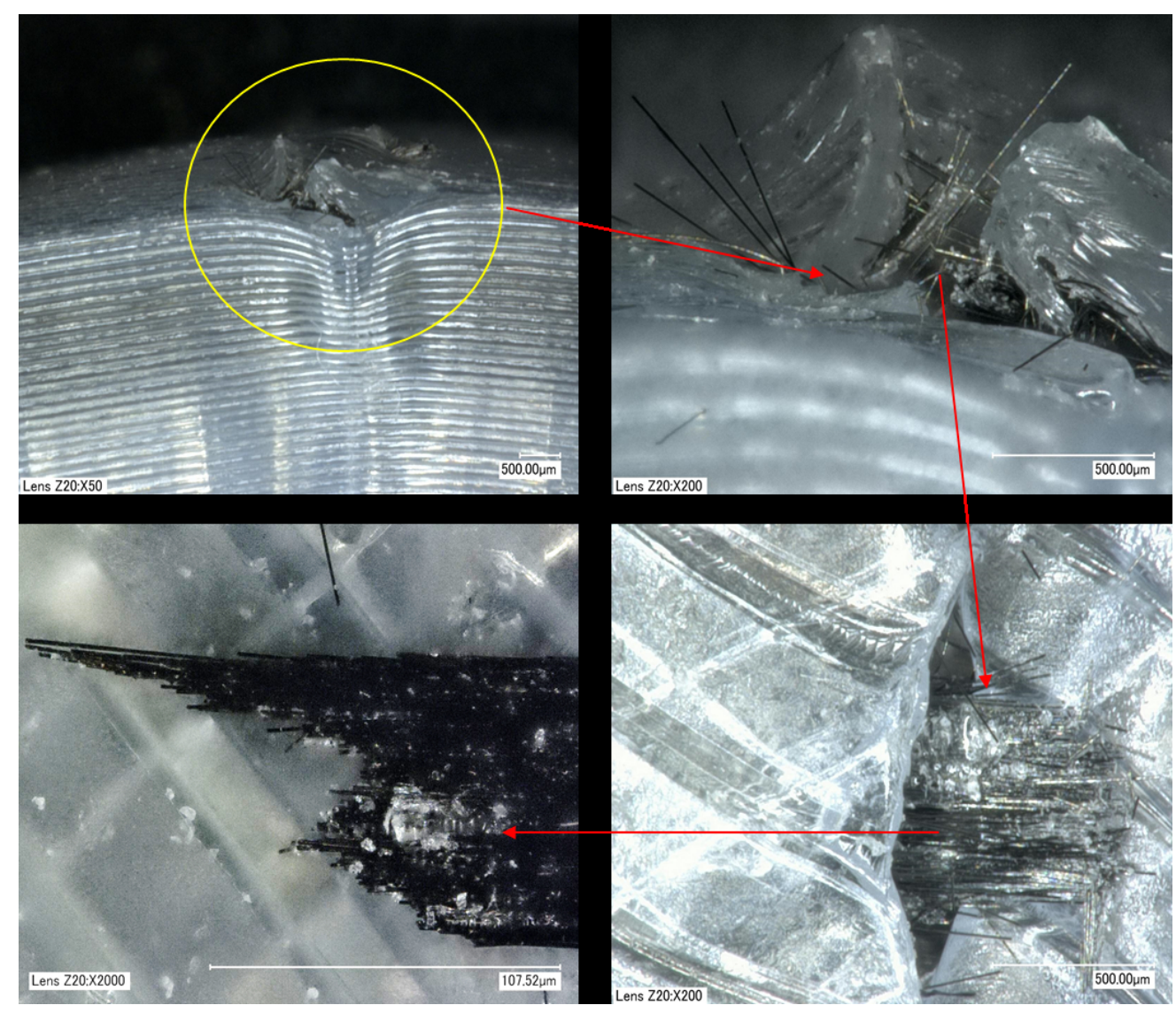

Figure 10 - Failure mode: Tensile fracture of the fibres $178 \times 153 \mathrm{~mm}(150 \times 150 \mathrm{DPI})$ 


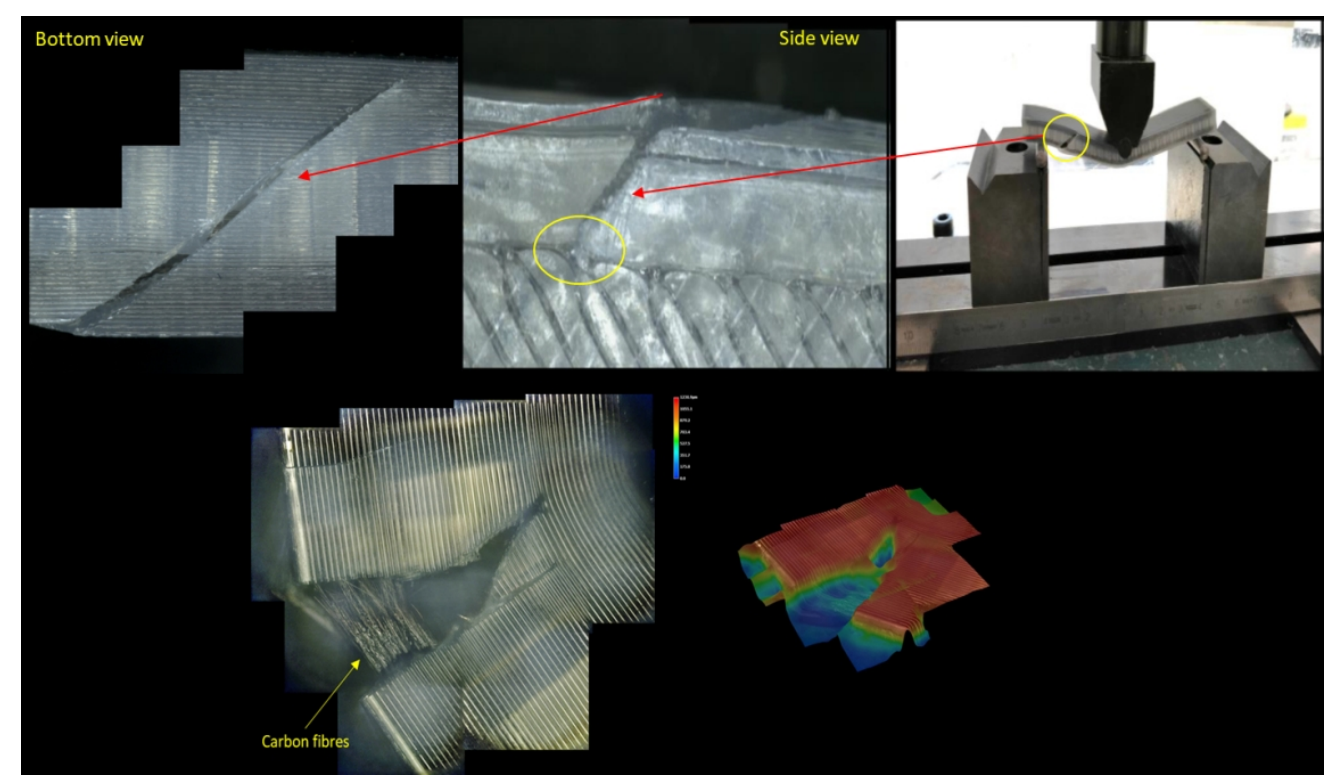

Figure 11- Failure mode: Tensile fracture of the outermost layer $237 \times 138 \mathrm{~mm}(150 \times 150 \mathrm{DPI})$ 


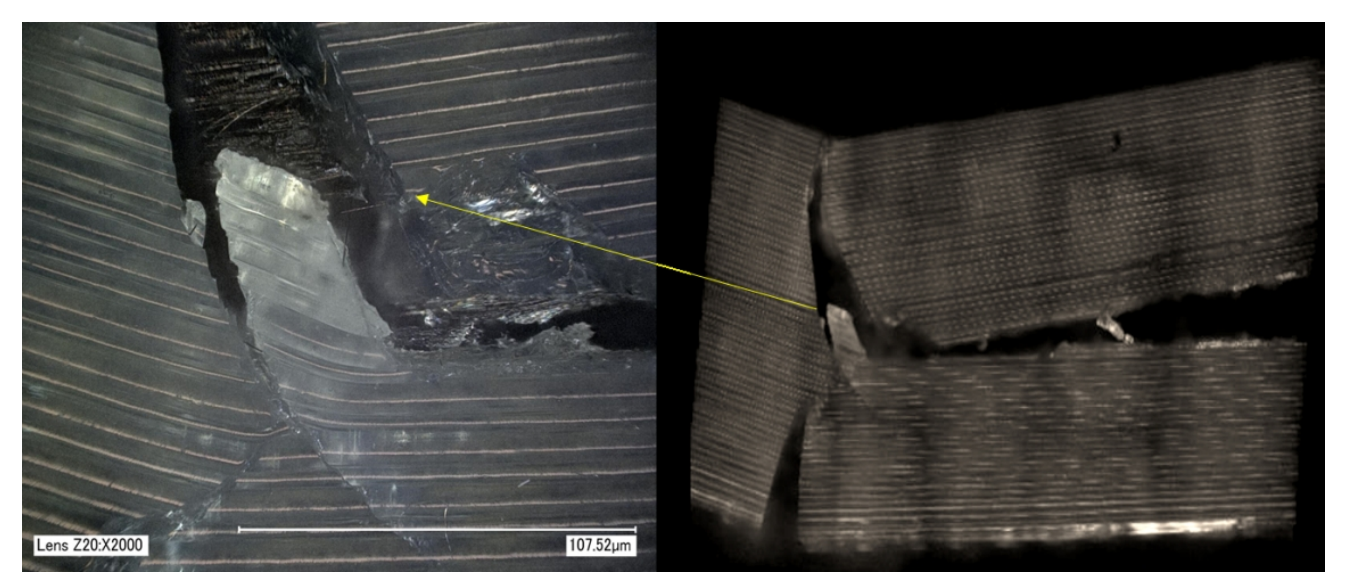

Figure 12- Failure mode: Delamination $225 \times 95 \mathrm{~mm}(150 \times 150 \mathrm{DPI})$ 


\title{
3D PRINTING OF COMPOSITES: DESIGN PARAMETERS AND FLEXURAL PERFORMANCE
}

\begin{abstract}
3D printing of composites has a high degree of design freedom which allows for the manufacture of complex shapes which cannot be achieved with conventional manufacturing processes. This paper aims to assess the design variables that might affect the mechanical properties of 3D printed fibre reinforced composites. Markforged Mark-Two printers were utilised to manufacture samples using nylon 6 and carbon fibres. The effect of fibre volume fraction, fibre layer location and fibre orientation has been studied using three-point flexural testing. Flexural strength and stiffness of the 3D printed composites increased with increasing the fibre volume fraction. The flexural properties were altered by the position of the fibre layers. The highest strength and stiffness were observed with the reinforcement evenly distributed about the neutral axis of the sample. Moreover, unidirectional fibres provided the best flexural performance compared to the other orientations. 3D printed composites also showed various failure modes under bending loads. Despite multiple studies available on 3D printed composites, there does not seem to be a clear understanding and consensus on how the location of the fibre layers can affect the mechanical properties and printing versatility. Therefore, this study covered this design parameter and evaluated different locations in terms of mechanical properties and printing characteristics. This is to draw final conclusions on how 3D printing may be used to manufacture costeffective, high quality parts with excellent mechanical performance.
\end{abstract}

Keywords: Additive manufacturing; Composites; Markforged; Carbon fibre/Nylon; Volume fraction; Fibre location; Fibre angle; Flexural testing

\section{Introduction}

3D printed fibre reinforced plastic composite products have the potential to be the future of high strength and low weight manufacturing and may replace the traditional manufacturing processes for some highperformance applications. Traditional manufacturing processes are so prevalent because of their ability to mass produce components with rapid cycle times and large batch sizes, the adoption of flexible automation has dramatically reduced the manufacturing costs (Waurzyniak, 2012). In high volume manufacturing, traditional processes are very cost effective, and the high initial tooling cost and capital investment are amortised across the volume of parts produced. Traditional manufacturing produces components with desirable mechanical properties; however, this can be at the expense of weight, which is not ideal for industries where the weight of a component is critical such as aerospace and commercial automotive industries (Kelly et al, 2015) (Mills, 2001). Advanced composite manufacturing techniques which utilise fibres have enabled components to be produced with more desirable mechanical properties whilst maintaining or reducing the weight of the component, increasing uptake in high tech production. $3 \mathrm{D}$ printing is an example of additive manufacturing and is now allowing components to be prototyped 'in house' affordably and allows specialised components to be manufactured in small production runs with minimal tooling cost. This process also allows for the construction of very complex geometries that are difficult with traditional processes such as components with hollow or honeycomb interior volumes. Therefore, it is reasonable to suggest that successful adaptation of 3D printing technologies to composite materials could enable a simple composite manufacturing method with lower production cost and a high degree of automation (Blok et al, 2018). As reinforcements can be accurately placed, 
the laminated structure of composite parts can be further optimised in each layer, allowing for an increase in design freedom and mechanical performance.

Typically, 3D printers use a plastic filament such as Nylon, ABS or PLA which produce components with weak mechanical properties in comparison to mass produced parts due to undesirable material properties and inherent manufacturing defects (Jenkins, 2017). Mechanical properties of 3D printed parts, however, can deviate significantly from the material bulk properties due to the specifics of how a structure is formed on the meso-scale during printing (Markforged, 2017). The parts produced will be final products however some parts may require post processing to achieve desired production quality. Combining composite fibres with the traditional 3D printing process may be the solution to bridging the gap between the 3D printing process and composite fibre process and should enable production of components with complex structures, with all or most of the strength of a similar part produced with traditional machining processes. In addition, allowing for small batch or prototype production at a similar cost as a large batch using the same process (Mims, 2016). A disadvantage of the continuous fibre printer is the limited control over the fibres' placement and the creation of voids when printing complex shapes. To overcome these disadvantages, a thermoplastic filament reinforced with short fibres above the critical fibre length has been proposed (Blok et al, 2018).

A general overview of 3D printable composite materials was provided by (Kalsom et al, 2016) and (Wang et al, 2017); while the engineering aspects of 3D printing as a composite manufacturing method was covered in more details by (Blok et al, 2018). Markforged printers deposit continuous fibres (carbon, glass or Kevlar) in a Nylon matrix. Although the printed parts using Markforged carbon fibres and nylon materials and printers have strength and stiffness of $700 \mathrm{MPa}$ and $50 \mathrm{GPa}$ respectively (Markforged, 2017), their nylon is very sensitive to water absorption, which plasticizes the matrix and can lead to a decrease in strength of up to $33 \%$ (Valentin et al, 2018). Despite that, Markforged printers and materials are still the market favourite when it comes to printed composites and still offers better properties compared to other printing technologies of composites. Other printing techniques have been developed by (Yang et al, 2017) and (Matsuzaki et al, 2016) but low fibre volume fraction limitation and decreases in some of the mechanical properties were reported.

In this paper, 3D printed carbon fibre/nylon composites have been presented and the performance of the different structures printed have been investigated. A detailed consideration of the processing parameters including various fibre volume fractions, fibre layer locations and fibre orientations which dictate the final part quality have been covered. The aim is to identify to what extent the design variables of $3 \mathrm{D}$ printing may influence the mechanical behaviour if it is to be used as a composite manufacturing method. The flexural response of the printed materials has been measured and comparisons were made between them in terms of mechanical properties and failure modes. A MarkTwo 3D printer was used to print continuous carbon fibre / Nylon composite specimens.

\section{Research Method}

\subsection{Sample Preparation}

Markforged Mark-Two 3D printer was used to manufacture test samples with dimensions (100 $\mathrm{mm} \mathrm{x}$ $20 \mathrm{~mm} \times 7 \mathrm{~mm}$ ) constructed from Markforged's Nylon 6 and Carbon fibre with triangular infill percentage of 50\% and isotropic fibre fill type (Markforged Inc, 2017) (Wang et al, 2014). The 3D printing process includes slicing a an STL file into discrete layers and then building that part layer by layer. In the FFF (fused filament fabrication) process, this happens by precisely extruding 3D printing solid thermoplastic materials through a hot nozzle in discrete tool paths that trace the outside of a laye 


\begin{abstract}
and its celled infill. The printed viscous material solidifies on the print bed which allows build-up of the component or part. At the beginning of each layer, the print bed is set at a given height and the gantry motion system moves the print head along the tool path as the extrusion system deposits material (Markforged Team, 2019). Markforged's slicing software which is called "Eiger" was used to adjust the printing parameters. This software does not allow for user adjustment of key printing parameters such as temperature, nozzle movement or extrusion speed which limits the printing capabilities as the printing settings cannot be fully customized (Blok et al, 2018).
\end{abstract}

The experiment performed is based on British Standards BS EN ISO 14125:1998+A1:2011 with some notable adjustments. The Class IV preferred specimen dimensions do not allow enough flexibility of layer locations. The 4-millimetre thickness limits the possible number of fibre layer locations to 8 as the layer height of the printer is limited to 0.125 millimetres for carbon fibre layers and 4 roof and 4 floor layers are required. Increasing the thickness of the samples to 7 millimetres allows for 48 possible locations for fibre layers.

The quality of a print is partially dependent on how 'flat' the print bed is. Markforged's TrueBed allows for the print bed to be removed and replaced easily and will realign with a $10 \mu \mathrm{m}$ accuracy and therefore only requires the print bed to be levelled periodically. High quality prints also depend on having a clean even surface to print onto, and therefore prior to each print the print bed will be washed to remove traces of adhesives and contamination. Adhesive is applied manually to the print bed in areas that will be printed upon, this is to limit the effect of warping and separation of the work piece from the print bed.

\title{
2.2. Design Variables
}

The volume fraction of carbon fibres was increased from $0 \%$ to $64.78 \%$, the latter value is maximum fraction of fibre possible in the samples due to wall and roof/floor layers (these layers remain constant and are outlined in Table 1). The orientation of the fibres for all samples 1-19 is unidirectional. Markforged's Eiger software is used to change the number of fibre layers in turn changing the volume fraction of fibre present in each sample. The fibre volume fraction $\left(V_{f}\right)$ was calculated using the volume of fibre and plastic for each sample estimated by Eiger software in $\left(\mathrm{cm}^{3}\right)$ using the following equation $\left(V_{f}=\right.$ [fibre volume / (fibre volume +plastic volume) $] \times 100$ ). This is not the exact representation of the fibre volume fraction since the fibres themselves have some nylon to help with laying them down during the printing. Markforged's software is a closed system allowing for tight control over every step, from creating print files to material filament to printing this allows for accurate estimation for these values. Samples 0-19 (table 1) are tested to measure the effect of volume fraction on the flexural properties. The control sample 0 is comprised solely of nylon and is used to compare the effects of adding carbon fibre reinforcement to the samples. In table 1, the fibre layers are described from the bottom (in contact with the print bed) of the test specimen to the top. The layers are described by the number of layers followed by a letter outlining the material $(\mathrm{N}=$ Nylon, $\mathrm{C}=\mathrm{Carbon}$ fibre), and vertical bar indicates a material change.

Table 1 - Fibre volume fraction of 3D printed specimens

Samples with different layer configurations are used to test the effect of the location of the fibre reinforcement layers on the samples' flexural properties. All samples have a total of 10 UD fibre layers and 46 nylon layers, table 2 . The four configurations being tested are, figure 1 :

- Two medium fibre layers located at the outside edge of the sample (sample 5)

- Single thick centrally located layer on the neutral axis of the sample (sample 20)

- Five thin evenly distributed layers about the neutral axis of the sample (sample 21)

- Two medium fibre layers located between the edge and the neutral axis of the sample (sample 22) 

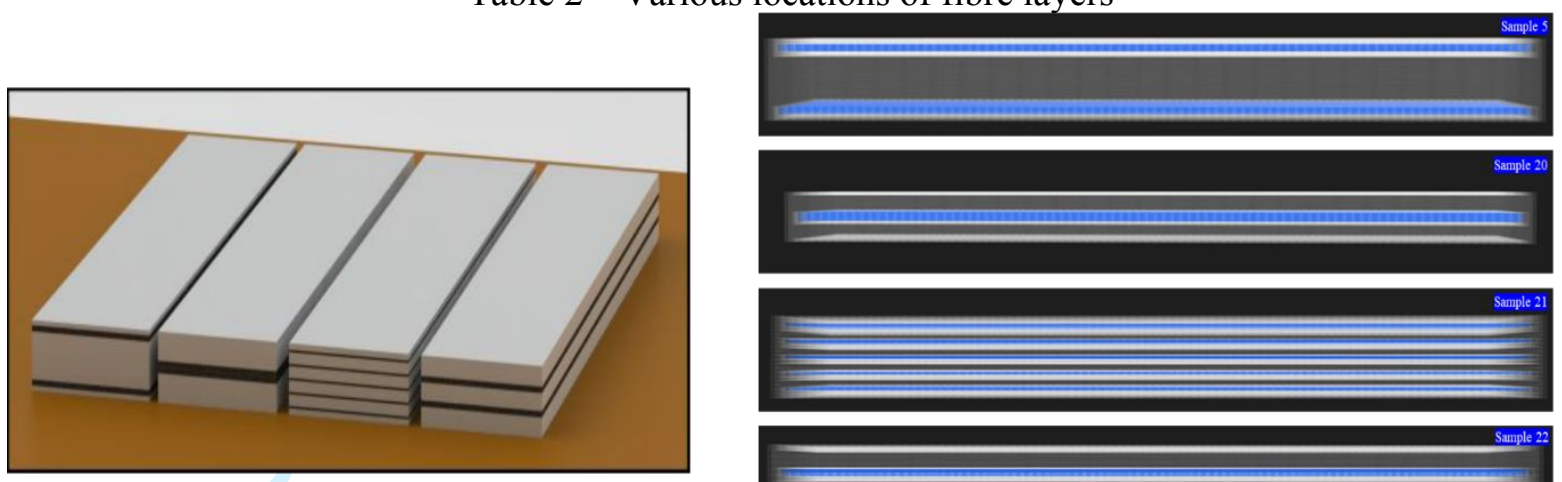

Table 2 - Various locations of fibre layers

Figure 1-Examples of fibre layer locations (Samples 5, 20, 21 \& 22 from top to bottom)

With regard to the fibre orientation, five different orientations have been printed and tested UD, $+45^{\circ} / 45^{\circ},+45^{\circ} /-45^{\circ},+90^{\circ} /+90^{\circ}$ and $+90^{\circ} /+0^{\circ}$. Models of these samples on a print bed are shown in Figure 2. All samples are symmetrical about their neutral axis. The orientation of fibre layers, figure 2 , are varied within samples 5, 23, 24 and 25. 46 nylon layers and 10 fibre layers positioned at the top and bottom edge of the sample ( 5 layers at each edge) were used, table 3.
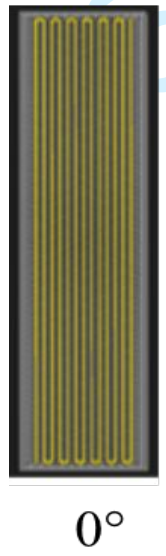

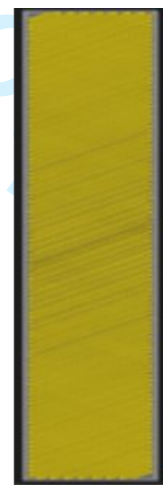

$45^{\circ}$

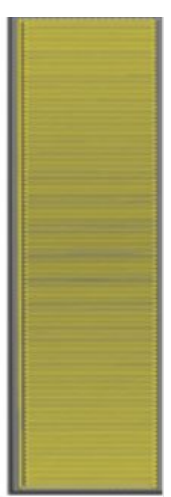

$90^{\circ}$

Figure 2-Fibres orientations

Fibre orientation is defined as the angle from the neutral axis of the test specimen to the direction of the fibre, Figure 3.

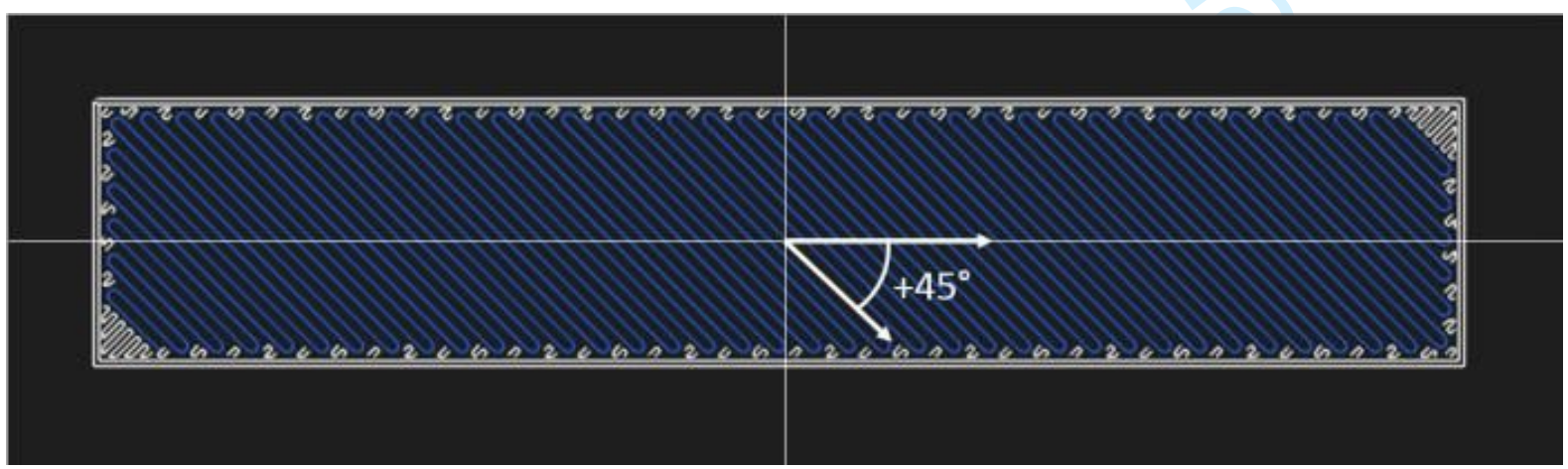

Figure 3 - fibre layer cross-section 
Table 3 - Various fibre orientations

\subsection{Testing}

Flexural testing was conducted using a Hounsfield H25KS universal testing machine with a $25 \mathrm{kN}$ load cell installed. The Hounsfield was configured for a three-point flexure test according to British Standards BS EN ISO 14125:2011. A three-point bend fixture was used with two $5 \mathrm{~mm}$ (diameter) support rods and 80-millimetre span. A constant displacement rate of $2 \mathrm{~mm} / \mathrm{min}$ was used and the force and displacement were directly measured from the machine with a $25 \mathrm{kN}$ load cell. Digital Microscope capable of creating multiple depth focused images and large stitched images was also used to inspect the fractured area and identify the failure modes.

\section{Results and Discussion}

\subsection{Effect of Fibre Volume Fraction}

The effect of increasing the fibre volume fraction on flexural performance was investigated using samples 0-19. The relation between carbon fibre volume fraction and the flexural properties shown in Figures 4-5 shows that the flexural strength and modulus increased with increasing the volume faction of the fibres up to $23 \mathrm{GPa}$ and $450 \mathrm{MPa}( \pm 1.0 \%)$ respectively. The flexural strength of the material increased from $30 \mathrm{MPa}$ at $0 \% V_{f}$ up to $450 \mathrm{MPa}$ at $65 \%$, and similarly the flexural modulus increased from $0.84 \mathrm{GPa}$ at $0 \% V_{f}$ up to $22.5 \mathrm{GPa}$ at $65 \%$. This is predicted as the reinforcement phase has a greater resistance to bending (stiffness) when compared to the continuous phase it is replacing, when increasing the volume fraction. The flexural strength is lower than the flexural strength expected for high quality fibre composites (Wisnom, 1992). This reduction in strength can be attributed to a poor fibre/matrix interface, poor layer/layer bonding and/or a high void content $(10 \%)$ as crack initiators which lead to immature failure (Blok et al, 2018). During printing, the material cools down in the printed layer before the next layer is printed which may induce residual stresses leading to reduction in properties. This can be investigated further by subjecting the material to annealing at temperature close to the $\mathrm{Tg}$ of the nylon to release the residual stress. Therefore, it can be said that, the quality of 3D printed composite is still not as good as the quality of automotive and aerospace grade composites, and for this material to be used in high performance applications, their strength and stiffness must be improved alongside keeping the quality of manufactured parts consistent. Although 3D printers are easy to use and do not require a lot of labour, they are unable to provide high consolidation and thus improve the printed part quality since they cannot apply additional pressure and heat to the printed part compared to the conventional manufacturing methods of composites such as vacuum bagging/autoclave processes and automated fibre placement.

Moreover, the flexural strength (165 MPa) and flexural modulus (8 GPa) obtained in this study at 50\% triangular fill and $28 \% V_{f}$ are lower than the strength $(363.8 \mathrm{MPa}$ ) and flexural modulus (46.9 GPa) obtained at $100 \%$ triangular fill and $27 \% V_{f}$ (Blok et al, 2018).. This shows the dependency of the properties on the infill percentage where the composite can withstand higher stress at higher volume fraction of the matrix. Therefore, there is a need for clear understanding of how printing parameters may affect the quality of the $3 \mathrm{D}$ printed composites part. 


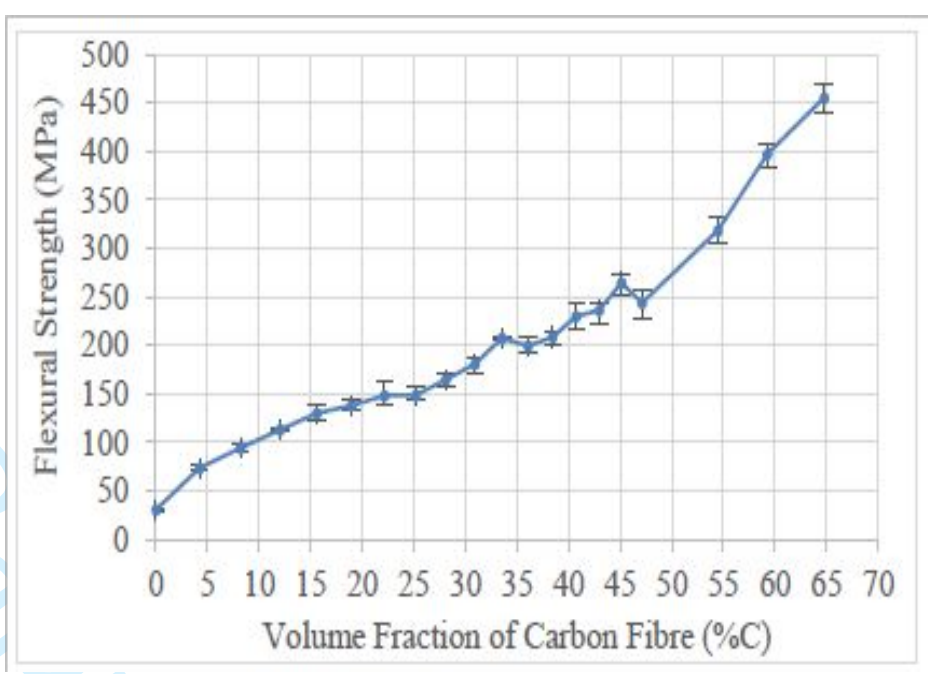

Figure 4 - The relationship between volume fraction and flexural strength

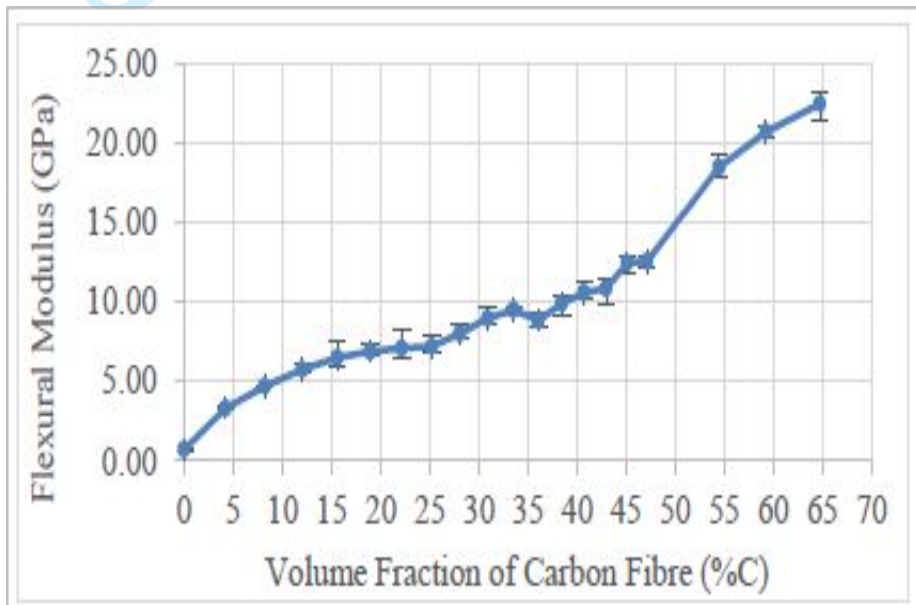

Figure 5 - The relationship between volume fraction and flexural modulus

\subsection{Effect of Fibre Layer Location}

Another important printing parameter is the location of the fibre layers within the printed part, figure 1. Eiger software normally attempts to create a sandwich panel, which is the aerospace version of an IBeam. By default, it will place fibre layers on the top and bottom of the part. Sandwich panels help ensure part strength while still maintaining an optimal strength-to-weight ratio, this is because the top and bottom layers will mainly be subjected to compressive and tensile stresses respectively when subjected to bending. But well-chosen fibre layer locations may dramatically increase the strength of the printed parts. Therefore, the effect of changing the location of the fibre reinforced layers within a sample was studied using samples 5 and 20-22, table 2 .

The results of the flexural test performed on samples with different locations of carbon fibre layers are shown in figures 6 and 7. Although composite theory predicts that the sample with the reinforcement closer to the upper and lower surfaces of the beam will have the highest strength and stiffness compared with other designs, calculating the average flexural strength of the four-samples tested revealed that thin evenly distributed fibre layers (sample 21) which resembles sandwich panels stacked on top of each other resulted in highest strength and stiffness of $154 \mathrm{MPa}$ and $7.3 \mathrm{GPa}$ respectively. While the strength and stiffness of the other samples 5 (sandwich-like panel), 20 and 22 are 138, 57 and $107 \mathrm{MPa}$ and 6.8, 1 and $3 \mathrm{GPa}$ respectively. This can be due to increasing core strength of sample 21 sandwich composites, 
which is due to strong carbon fibres evenly distributed in the part. This design parameter also proves that the quality of the final printed part is dependent on the where the fibre layers are positioned with the optimal structure of sandwich panels with extra fibre layers evenly distributed between the top and bottom fibre layers.

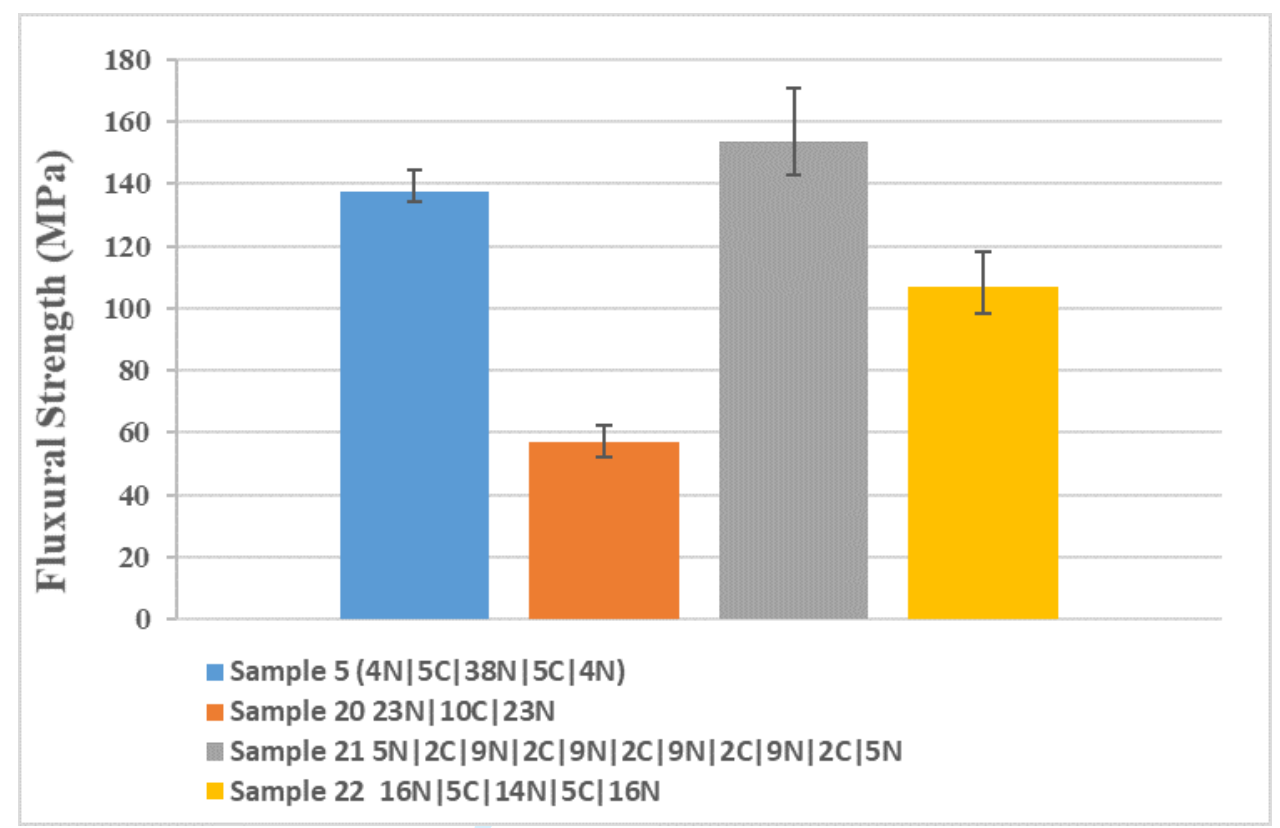

Figure 6 - Averaged flexural strength for different fibre locations

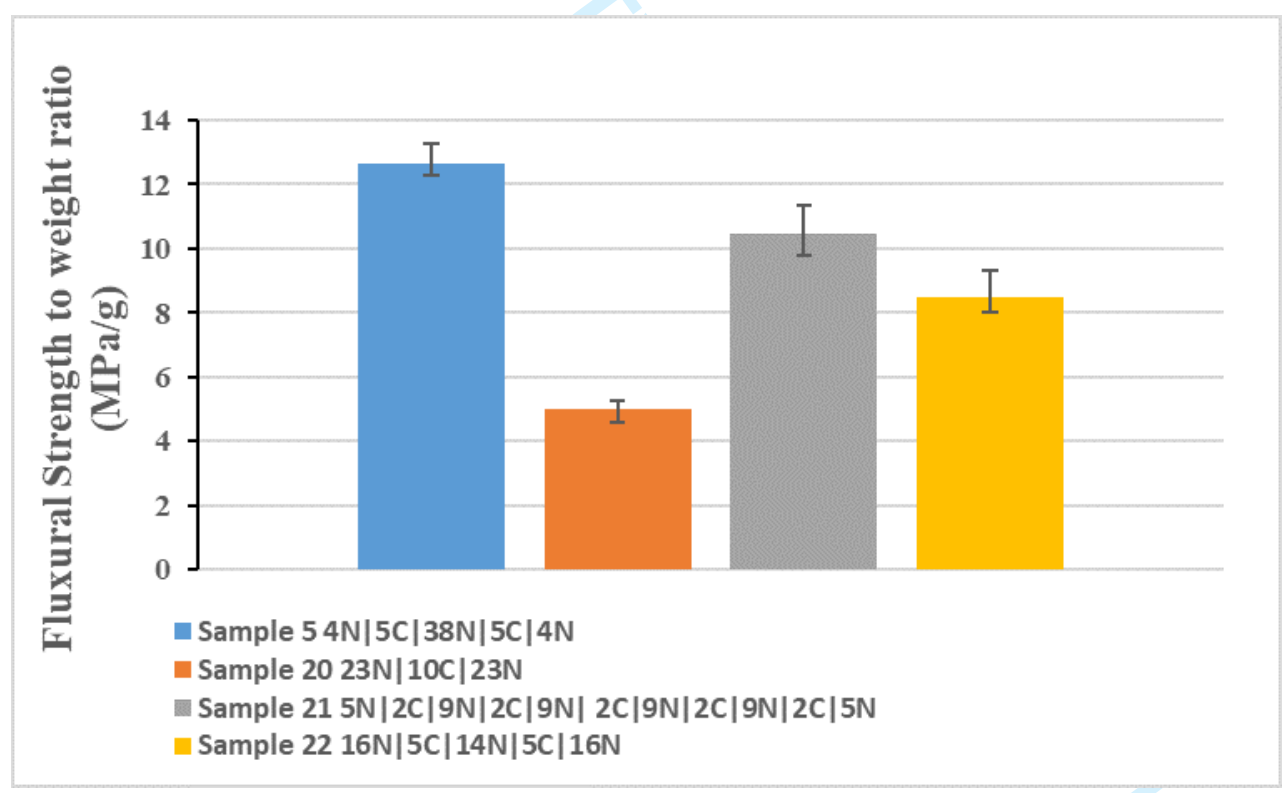

Figure 7 - Averaged flexural properties and their average -to-weight ratios for different fibre locations

\subsection{Effects of Fibre Orientation}

The effect of fibre orientation on the flexural properties was investigated using samples 5 and 23-26. Five fibre layers were placed at both top and bottom of the samples for all the different orientations. It must be noted that many of the samples produced with different fibre orientations experienced warping once removed from the print bed, this warping is likely a result of residual stress within the samples caused by the off-axis fibre. This warping caused some samples to displace transversely on the support 
rods of the test fixture, this may reduce the energy transferred into deflecting the test beam for a given recorded load.

Figure 8 shows that unidirectional samples have the highest flexural strength and modulus with strength of $138 \mathrm{MPa}$ and stiffness of $6.9 \mathrm{GPa}$ compared to strength of 48, 53, 43 and $48 \mathrm{MPa}$ and stiffness of $1.7,1.6,1.5$ and $2.3 \mathrm{GPa}$ for $+45^{\circ} / 45^{\circ}, \pm 45^{\circ}, 90^{\circ} / 90^{\circ}$, and $90^{\circ} / 0^{\circ}$ respectively. This can be due to the placement of the strong unidirectional fibres at the tension side of the flexural sample which led to a remarkable increase in the properties and the resistance against initial fracture, figure 9. Crosslaminated samples $\left(+45^{\circ} /-45^{\circ}\right.$ and $\left.+90^{\circ} /+0^{\circ}\right)$ were stronger than their non-cross-laminated counterparts $\left(+45^{\circ} / 45^{\circ}\right)$ and $\left(+90^{\circ} /+90^{\circ}\right)$ which can be due to the slight dependency on the fibre properties rather than the matrix properties for the latter cases. These samples also experienced less lateral deflection, a deformation caused by torsional effects.
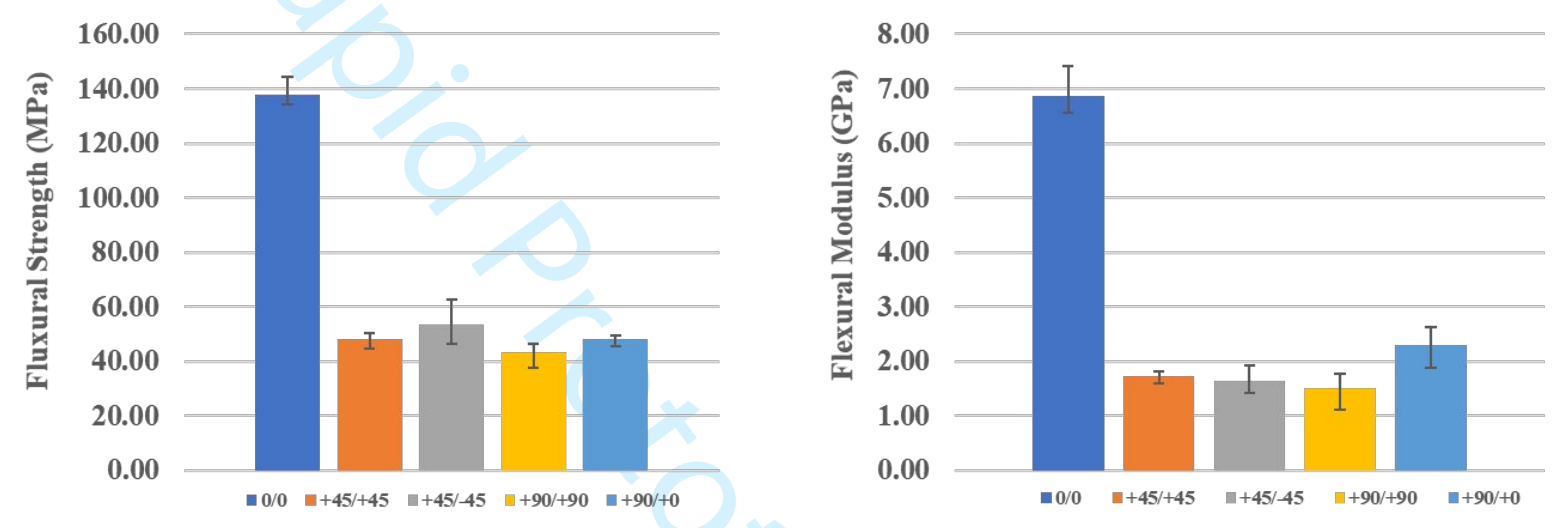

Figure 8 - Relationship Between Fibre Orientation and flexural Properties

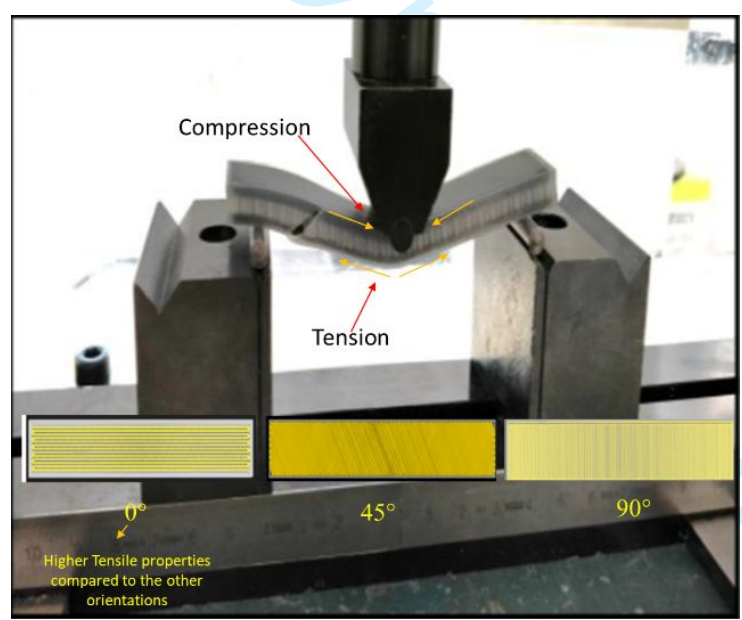

Figure 9 - Relationship Between Fibre Orientation and flexural loads

\subsection{Failure modes}

Failure modes observed during experimentation of UD samples varied between sample design and within repeats of the same design. The classification of failure modes has been checked against BS EN ISO 14125:2011. Batch-to-batch variation of repeats can be an indicator of printing defects and should be considered when designing components. Three common failure modes were observed. In the first mode, samples failed as a result of a tensile fracture of the fibre, figure 10. In the second mode, specimens initially failed off centre from the central member. The tensile fracture of the outermost layer is highlighted in Figure 11. The highlighted region in Figure 11 shows a 3D printing discontinuity that 
is likely the location where the fracture of the outermost layer propagated from. The discontinuity is on the boundary of the outside walls of the print.

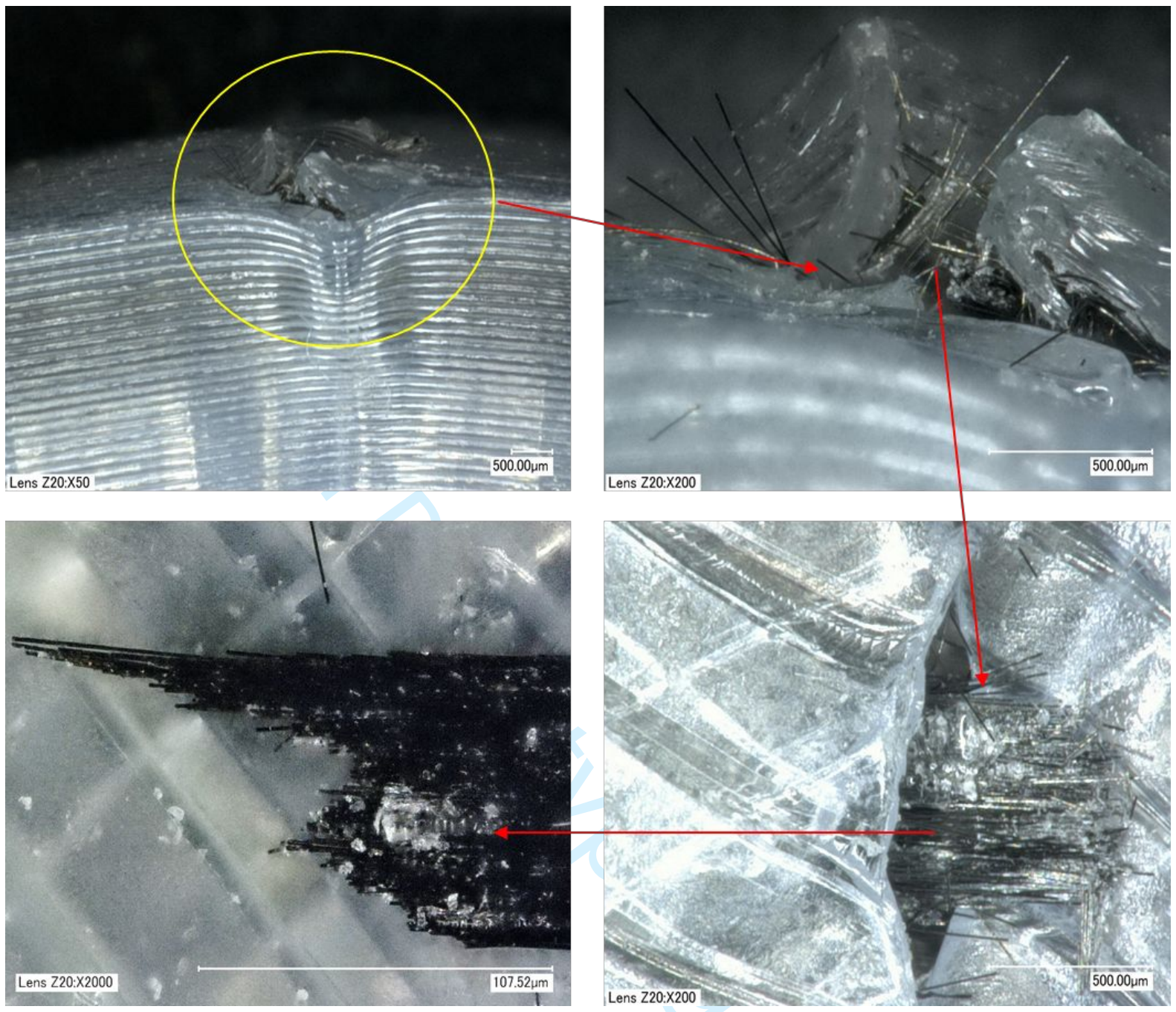

Figure 10 - Failure mode: Tensile fracture of the fibres 

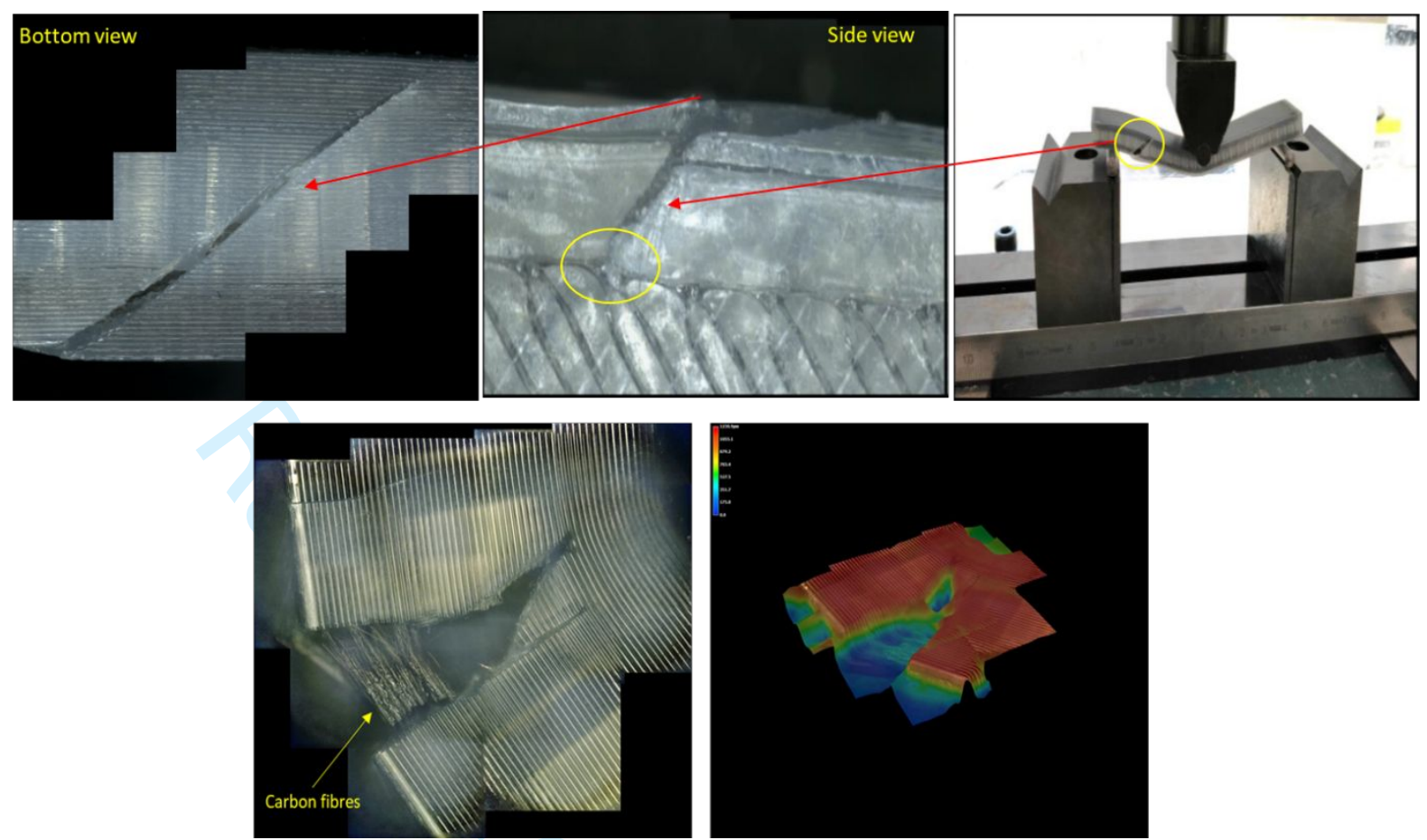

Figure 11- Failure mode: Tensile fracture of the outermost layer

In the third mode, samples experienced delamination. This can be seen in Figure 12 where samples failed at a lower strain than the other modes and the larger reduction in stress at the failure. The thin layer of nylon between the carbon fibre layers likely didn't provide strong adhesion and therefore stress was concentrated within that layer causing a crack to propagate perpendicular to the load direction (in the fibre direction).
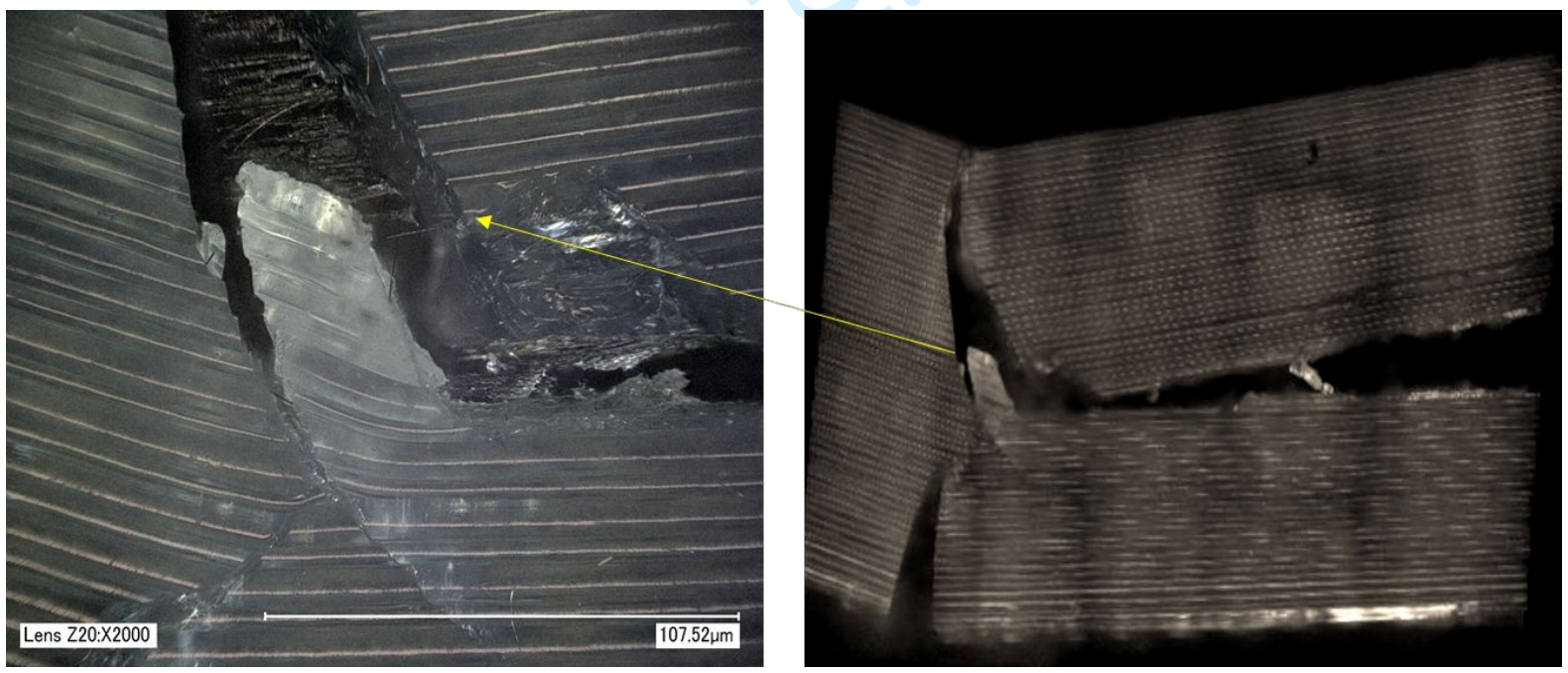

Figure 12- Failure mode: Delamination

The crack that propagated along the neutral axis of the sample caused a complete separation of the layers as seen in Figure 16. The failure caused very rough edges and occurred through multiple layers. A 3D printing delamination defect occurs when layers have poor cohesion however this typically effects a single layer boundary and therefore likely not the sole cause of the failure observed in sample $25 \mathrm{C}$. 


\section{Conclusion}

In this study the influence of key design parameters on the performance of 3D printed carbon fibre/nylon composites have been benchmarked with mechanical testing and optical microscopy. Markforged printers were used to print specimens with 50\% triangular infill nylon and various fibre volume fractions, fibre layer locations and fibre orientations. The flexural properties increased with increasing the volume fraction of the carbon fibres, therefore optimising volume fraction configurations depends on the application that a component will serve. For all components experiencing longitudinal bending a unidirectional fibre orientation produced components with flexural strength and modulus significantly higher than other fibre orientations. In terms of optimal location, these unidirectional fibre layers should be evenly distributed about the neutral axis of the parts mainly with layers close to the upper and lower surfaces of the part to produce components with the highest flexural strength and modulus. Although $3 \mathrm{D}$ printing is not yet the main stream in the composites field but by optimising the design parameters this may open the door for new applications for high performance 3D printed parts suitable for aerospace, automotive, sport and rapid prototyping applications.

\section{References}

Blok, L. G., Longana, M. L., Yu, H. and Woods, B. K. S. (2018), “An investigation into 3D printing of fibre reinforced thermoplastic composites". Additive Manufacturing, Vol.22, pp. 176-186.

Jenkins, S. (2017), “3-D printing for finished products”. Journal of Chemical Engineering, Vol.124, pp. $14-16$.

Kalsoom, U., Nesterenko, P.N. and Paull, B. (2016). "Recent developments in 3D printable composite materials", RSC Adv, Vol. 6 No.65, pp.60355-60371.

Kelly, J., Sullivan, J., Burnham, A. and Elgowainy, A. (2015), "Impacts of Vehicle Weight Reduction via Material Substitution on Life-Cycle Greenhouse Gas Emissions", Journal of Environmental Science \& Technology, Vol. 49, pp.12535-12542.

Markforged. (2017), "Building the Future of Manufacturing", available at: https://markforged.com/why-markforged/ (accessed 01 May 2019)

Markforged. (2016), "High Strength 3D Printing With Continuous Fibres", available at: https://markforged.com/ (Accessed 01May 2019)

Markforged Inc. (2017), "arkforged Materials Data Sheet", available at: http://www.rpsupport.co.uk/downloads/rps_markforged_data sheets/markforged materials datasheet .pdf, (accessed 01 May 2019)

Markforged Team. (2019), “ 3D Printing Process”, available at: https://markforged.com/learn/3dprinting-process/, (accessed 30 October 2019)

Matsuzaki, R., Ueda, M. and M. Namiki. (2016), "Three-dimensional printing of continuous fiber composites by in-nozzle impregnation”, Scientific Reports. Vol. 6, pp. 23058.

Mills, A. (2001), "Automation of carbon fibre preform manufacture for affordable aerospace applications". Composites Part A. Vol. 32, pp.955-962.

Mims, C. (2016), "Keywords: What 3-D printing means for manufacturing", Dow Jones \& Company Inc, Hong Kong. 
Valentin, D., Paray, F. and Guetta, B. (1987), "The hygrothermal behaviour of glass fibre reinforced Pa66 composites: a study of the effect of water absorption on their mechanical properties", Journal of Materials Science, Vol.22 No.1, pp. 46-56.

Wang, H. W., Zhou, H. W. and Gui, L. (2014), “Analysis of effect of fiber orientation on Young's modulus for unidirectional fiber reinforced composites", Composites Part B: Engineering, Vol. 56, pp. $733-739$.

Wang, X., Jiang, M., Zhou, Z., Gou, J. and Hui. D. (2017), “3D printing of polymer matrix composites: a review and prospective", Composites. Part B, Vol.110, pp.442-458.

Waurzyniak, P. (2012), "Flexible automation for automotive", Journal of Manufacturing Engineering, Vol.149, pp.103-112.

Wisnom, M.R. (1992), “The relationship between tensile and flexural strength of unidirectional composites", Journal of Composite Materials. Vol.26 No.8, pp.1173-1180.

Yang, C., Tian, X., Liu, T., Cao, Y. and Li, D. (2017). "3D printing for continuous fiber reinforced thermoplastic composites: mechanism and performance", Rapid Prototype, Vol. 23 No.1, pp. 209-215. 